\title{
El proceso de mediación explícita en la escritura del bilingüe endógeno. Análisis de La otra gente, autotraducción del gallego al castellano por Álvaro Cunqueiro
}

\author{
Rexina Rodríguez Vega ${ }^{1}$
}

Recibido: 4 de marzo de 2016 / Aprobado: 29 de junio de 2017

Resumen: La autotraducción del escritor bilingüe endógeno acostumbra a poner de relieve de modo privilegiado los mecanismos que rigen en la construcción del discurso sobre el otro. Así, la presencia del heterolingüismo, que hace audible la mediación, puede considerarse una característica habitual en muchas de las autotraducciones intraestatales en las que la que la nota o la glosa aparecen incorporadas en el cuerpo mismo del texto lo que modifica el estatus de la ficción.

Esta tolerancia hacia la alteridad lingüística acostumbra a presentar también fuertes límites. Dentro de un marco de relaciones de poder asimétricas, como lo son las relaciones entre las literaturas gallega, catalana y vasca con la de expresión castellana, solo se asumen como tolerables aquellos textos que ocultan el conflicto sociolingüístico propio de las situaciones de contacto.

Palabras clave: Álvaro Cunqueiro; heterolingüismo; autotraducción; contacto de lenguas; diglosia literaria; transculturalidad e hibridismo.

[en] The process of explicit mediation in of the endogenous bilingual writers. Analysis of La otra Gente, self-translation from Galician to Castilian by Álvaro Cunqueiro

\begin{abstract}
The self-translation of the endogenous bilingual writer tends to emphasize the mechanisms of discourse about the other. The presence of heterolingualism, which makes mediation audible, can be considered a habitual feature in many interstate self-translations in which comments are integrated into the body of the text and alter the status of fiction.

This tolerance towards linguistic otherness also tends to present strong limits. Within a framework of asymmetric power relations, such as the relations between Galician, Catalan and Basque literatures with that of Castilian expression, only those texts that conceal the sociolinguistic conflict typical of contact situations are assumed as tolerable.
\end{abstract}

Keywords: Álvaro Cunqueiro; heterolingualism; self-translation; languages in contact; diglossia; Transculturality and Hybridization.

Sumario: 1. El autotraductor como bilingüe endógeno. 2. El autor-traductor como intermediario. 3. La mediación en las escrituras bilingües. 4. Xente de aqui e acolálLa otra gente de Álvaro Cunqueiro, un ejemplo de mediación bilingüe. 4.1. Del “QQuiénes somos?” al "Nosotros somos así”. Reduccción pragmática y lectura de grupo 4.2 El tratamiento de los referentes culturales. 4.2.1 Referencias geográficas. 4.2.2 Antropónimos. 4.2.3. Fiestas y romerías populares. 4.2.4 Costumbres o tradiciones gallegas. 4.3 El reflejo de alteridad lingüística. 5. Conclusión. 6. Referencias bibliográficas.

$1 \quad$ Universidade de Vigo 
Cómo citar: Rodríguez Vega, R. (2017). El proceso de mediación explícita en la escritura del bilingüe endógeno. Análisis de La otra gente, autotraducción del gallego al castellano de Álvaro Cunqueiro, en Revista de Filología Románica 34.2, 281-297.

\section{El autotraductor como bilingüe endógeno}

Tal y como indica Josep Miquel Ramis (2014: 38), uno de los párametros fundamentales a la hora de establecer una taxonomía de la autotraducción es aquel que tiene en cuenta el marco político. De acuerdo con este vector, pueden diferenciarse las llamadas autotraducciones trans-lingüísticas o intraestatales, marcadas por el ejercicio de un bilingüismo endógeno, de aquellas intertestatales realizadas por individuos bilingües en sociedades monolingües.

Esta diferencia se complementa con otra distinción que atañe a las relaciones de poder entre las lenguas. De acuerdo con Pascale Casanova (2002) que, desde una óptica sistémica, llama la atención sobre la asimetría de las relaciones traductológicas, Rainer Grutman (2011) deslinda la infraautotraducción de la supraautotraducción. La primera marca la dirección de la versión de un idioma simbólicamente dominante o central a un idioma "periférico"; la segunda, la del idioma dominado o minoritario al idioma dominante.

El análisis de las marcas que estos condicionantes sociopolíticos dejan en las versiones resulta altamente revelador de las tensiones propias de los territorios caracterizados por una situación de contacto de lenguas. Tanto desde el punto de vista estrictamente traductológico como desde el campo de la sociolingüística y de la socioliteratura, las operaciones observables en las traducciones de escritores gallegos, catalanes y vascos al castellano nos ayudan a entender el intrincado panorama peninsular. Es importante destacar también el hecho de que la reproducción de la alteridad lingüística en el texto no obedece a una simple reproducción de lo real, puesto que implica una selección de rasgos elegidos en función de criterios funcionales internos a la estructura de la obra (Lane-Mercier 1989). Tal y como indica Myriam Suchet en su esclarecedora tesis de doctorado Textes hétérolingues et textes traduits : de " la langue aux figures de l'énonciation. Pour une littérature comparée différentielle (2010) - posteriormente publicada por Classiques Garnier bajo el título: L'Imaginaire hétérolingue. Ce que nous apprennent les textes à la croisée des langues (2014)en la literatura heterolingüe no se reproducen las situaciones de contacto lingüístico a la manera de un calco sino, más bien, a la manera de un mapa. Así mismo, la citada estudiosa propone abordar este tipo de textos partiendo de la base de que las representaciones lingüísticas que definen a una comunidad son en parte construidas en y por los textos literarios (Suchet 2010: 37).

\section{El autor-traductor como intermediario}

Frente a las traducciones alógrafas, el hecho de que sea el propio autor el encargado de realizar la labor de mediación puede acercarnos, como acabamos de indicar, a las normas, valores y usos del común de los bilingües endógenos. Liberado del fantasma 
de la invisibilidad, el autotraductor puede hacer audible su voz como mediador entre dos realidades lingüísticas y culturales. El desdoblamiento diálogico que necesariamente asume acostumbra a poner de relieve con especial nitidez las condiciones de enunciacion, inscribiendo en el texto marcas explícitas que remiten tanto al cambio de destinatario como a la propia reflexión sobre la identidad diglósica. En este sentido, podemos decir que los procesos de adecuación cultural presentan en las autotraducciones unos bordes mucho más definidos. La tendencia a la preservación del heterolingüismo ${ }^{2}$, de la diferencia resistente de la cultura de origen se resolverá de modos diversos, oscilando entre el procedimiento de exotización y la marca del conflicto identitario.

\section{La mediación en las escrituras bilingües}

De entre las propuestas tipólogicas que buscan ahondar en la relación entre bilingüismo y escritura Christian Lagarde (2001:50-58) distingue, por ejemplo, tres modalidades: el tipo "color local", el tipo "dar a conocer" y el tipo "lucha de lenguas".

En el primer caso, la presencia de la otra lengua-cultura se presenta bajo la óptica del exotismo, de acuerdo con una actitud condescendiente y marcada por el estereotipo. En el segundo caso, sin embargo, la alteridad lingüística se asume como propia de la esfera de la identidad, de la intimidad del escritor. Es la conciencia del valor de la lengua-cultura dominada la que impulsa, pues, al autor a visibilizar esa realidad en la cultura dominante. A fin de subrayar la originalidad (que habitualmente manifiesta mediante el comentario epilingüistico con abundante recursos a la adjetivación valorizante), el autor se transmuta en etnólogo o antropólogo cumpliendo el papel de intercesor tanto en el plano del significante como en el del significado.

El tercer tipo, el de la "lucha de lenguas", comparte con el "dar a conocer" la fuerte presencia de la lengua vernácula. Sin embargo, frente a la imagen de coexistencia pacífica entre las lenguas en contacto que se deriva de los textos pertencientes al segundo tipo, en este caso se ponen en evidencia las relaciones conflictivas entre las lenguas dominante y dominada. Si en el "dar a conocer" prevalece un funcionamiento diglósico que busca, sobre todo, estrategias de compensación para la lengua dominada, en el de la "lucha de lenguas" la confrontación entre dos códigos lingüísticos pasa a primer plano. El texto reproduce así las tensiones sociolingüísticas, socio-culturales, socio-políticas y socio-económicas de una colectividad.

Un enfoque diferente, aunque complementario, de esta cuestión es el ofrecido por Rainer Grutman (2012). Para este estudioso la vivencia de la diferencia lingüística puede cristalizar en dos tipos básicos de textos, el bilingüe y el diglósico. La diferencia fundamental estribaría en el tipo de contrato de lectura que postulan. Así, en los textos diglósicos es posible encontrar una enunciación bífida que prevé un doble destinatario implícito, un doble público lector: el endógeno y el exógeno.

El término, acuñado por Rainier Grutman, rehuye las polémicas nociones de "diglosia” y "bilingüismo" y busca dar cuenta de la especificidad del uso literario del contacto de lenguas. Así el neologismo es definido por el autor como: "la presencia en un texto tanto de idiomas extranjeros como de variedades (sociales, regionales o cronológicas) de la lengua principal» (Grutman 1997: 37) . 
La diglosia textual ${ }^{3}$, redefinida por Grutman (2005) a partir del concepto de diglosia literaria ${ }^{4}$ acuñado por Mackey (1976), se daría, pues, cuando son posibles dos lecturas que no son mutuamente excluyentes:

1) Una lectura bilingüe en la que la presencia del hibridismo lingüístico se convierte en un vector de construcción identitaria para los lectores endógenos, que son los únicos que están en disposición de comprender en su totalidad el juego de códigos.

2) Una lectura unilingüe en la que el lector exógeno percibe la alteridad y la acepta como una fuente de "exotismo" o "color local".

Desde un punto estrictamente traductológico, Myriam Suchet (2010) recurre al término de ethos para deslindar los diferentes modos de tratar la alteridad lingüística en la operación de trasvase. El término, proveniente de la Retórica de Aristóteles incide en el modo en el que en el orador fundamenta su credibilidad. Producido no por el contenido del discurso sino por la manera en el que este se muestra, el ethos pondrá pues el foco en la enunciación. Al aplicar esta noción a la técnica literaria Maingueneau (1999:78) apunta a la existencia de una "vocalidad específica" del texto. Kerbrat Orecchioni (2002: 173-196) retoma esta metáfora de la voz al insistir en la dimensión interaccional entre la imagen proyectada o reivindicada por el narrador y aquella que le atribuye el lector. Suchet, por su parte, utilizará esta noción de "voz" o de ethos para atacar el mito de la invisibilidad del enunciador en la traducción puesto que, tal y como afirma:

Il nous semble que tout texte traduit, même lorsqu'aucun dispositif ne met explicitement en scène la voix de son narrateur, produit lui aussi un ethos de son énonciateur (Suchet 2010:9).

Los continuos cambios de código que se producen en el texto heterolingüe revelan con especial nitidez una estrategia, construyen una imagen de la instancia enunciativa. Vista desde este prisma, la autotraducción entre lenguas en contacto se convierte en un espacio en el que rastrear con claridad la existencia de un locutor segundo que presenta un modelo de enunciación específico.

Entre la tipología de ethos a los que puede dar lugar la traducción del texto heterolingüe, Suchet identifica el ethos dialógico (2010: 9-11), que preserva el juego de códigos del texto original a condición de que este esté correctamente aislado y balizado; el ethos de obra (2010: 11), en el que el cambio de lengua indica el paso a

Para Grutman :

Dans la mesure où celui-ci (el autor diglósico) veut s'attirer deux publics largement incompatibles, il veillera à n'être ni trop prolixe pour les uns (les insiders) ni trop elliptique pour les autres (les outsiders). Or, quand cette cassure du public correspond à une frontière lingüistique interne socialment pertinente, mais qu'en même temps le texte maintient la tensión entre une lecture bilingüe et une lecture unilingue, sans que l'une soit sacrifiée à l'autre, je parlerai de diglossie textuelle (Grutman 2005: 10).

4 W. F. Mackey en su trabajo titulado « Langue, dialecte et diglossie littéraire» afirma:

En somme, on peut avoir diglossie formelle, la langue parlée étant une langue et la langue écrite en étant une autre; ou diglossie fonctionnelle, chaque langue possèdant son ensemble de fonctions. Lorsque cette répartition fonctionelle s'applique à la langue écrite, il peut y avoir de la diglossie littéraire (Mackey 1976: 42). 
un empleo poético del lenguaje y, por tanto, a una referencia intertextual; el ethos de mediación rechazada (2010: 11-12), que asume la opacidad que el código extranjero presenta para el lector sin pretender facilitar la comunicación y, por último, el ethos de mediación explícita (2010: 12) en el que la voz del traductor como locutor segundo se hace audible y dibuja una nítida imagen del lector implícito.

\section{Xente de aquí e acolá/ La otra gente de Álvaro Cunqueiro, un ejemplo de mediación bilingüe}

Tras la presentación de algunos de los vectores que caracterizan el trabajo del autotraductor como bilingüe endógeno, nos centraremos ahora en el análisis de un caso concreto, el de la autotraducción llevada a cabo por el escritor gallego Álvaro Cunqueiro de su obra Xente de aqui e acolá al castellano ${ }^{5}$, ya que consideramos que en ella se hacen especialmente visibles determinados aspectos de la mediación que pueden ser considerados como paradigmáticos de las relaciones que rigen el travase entre las culturas consideradas periféricas y central en el estado español.

Álvaro Cunqueiro, escritor monolingüe en gallego en poesía y teatro y claramente bilingüe en el ámbito de la novela y el periodismo literario, presenta la particularidad de haber autotraducido un buena parte de su obra narrativa del gallego al castellano. Podemos citar, entre otros títulos, Merlín e Familia e outras historias (1955) /Merlín y familia (1957), As crónicas do Sochantre (1956)/Las crónicas del Sochantre ${ }^{6}$ (1959), Si o vello Sinbad volvese ás illas (1961)/ Cuando el viejo Sinbad vuelva a las islas (1962) o Xente de aqui e acolá (1971)/ La otra gente (1975).

Entre las modificaciones que presentan las autotraducciones cunqueirianas sobresalen, por su inusual relieve, aquellas motivadas por el cambio de destinatario. Esto es lo que ocurre, por ejemplo, en la La otra Gente (1975), versión de Xente de aqui e acolá (1971), volumen de relatos en los que Cunqueiro pretende trazar un fresco de la realidad física y psicológica del mundo rural gallego.

A la hora de clasificar el corpus narrativo de Cunqueiro, los estudiosos coinciden en distinguir, frente a la indole declaradamente fantástica y maravillosa de sus novelas, el carácter realista de sus libros de relatos breves. Así, el profesor Basilio Losada afirma:

Hay en la obra de Cunqueiro dos lineas muy diversas y aparentemente contrapuestas: el mundo de la fantasía, de la creación (Merlín e Familia, As Crónicas do Sochantre, Tesouros Novos e Vellos, Si o Vello Sinbad Volvese ás Illas) y la visión jocunda y tiernísima de tipos extraídos de la vida rural gallega, que Cunqueiro conoce tan bien y ama con tan viva delectación: Escola de Menciñeiros (1960),

\footnotetext{
Álvaro Cunqueiro publica Xente de aqui e de acolá en 1971 en la editorial gallega Galaxia y su autotraducción, que lleva por título La otra gente, en 1975 en la editorial barcelonesa Destino.

6 A pesar de que la edición española presenta a Cunqueiro como único traductor, debemos indicar su carácter de "autotraducción compartida" (Santoyo 2012). La correspondencia entre el propio Cunqueiro y Francisco Fernández del Riego, amigo e impulsor de la editorial Galaxia -fundamental en el proceso de recuperación de la cultura gallega en el franquismo-, indica que es este último el responsable del trasvase lingüístico. Con todo, consideramos que la edición española es también relevante para el análisis que nos ocupa puesto que el autor participa en el proceso, supervisando la versión y proponiendo el añadido del peritexto "Epílogo para Bretones" y ciertas modificaciones en el texto de los Dramatis personae.
} 
Xente de Aquí e acolá (1971), Os outros feirantes (1979), son hitos relevantes de esta segunda línea, galerías de personajes extraídos del mundo campesino y con perfiles recreados desde una finísima captación de lo popular (Losada 1980: 46).

La especial valoración de la narrativa breve es compartida por Darío Villanueva, quien al acercarse a la concepción del realismo en Cunqueiro subraya como una de las principales contribuciones del escritor la introducción de la magia en la literatura costumbrista (Villanueva: 352 )

Camilo Gonsar expresa su predilección por obras como Xente de aquí e acolá en los siguientes términos:

Quixera, efectivamente, explicar, diante de todo, a miña predilección por obras como Xente de aqui e de acolá e outras semellantes. Podería afirmar que esta predilección é debida, en gran parte, a que estas obras supoñen unha espléndida ruptura cunha forte tradición da narrativa de asunto galego, sobre todo da escrita en castelán, tan proclive ao tema, perdón pola palabra, dos pazos en decadencia [...] refutando involuntariamente e pola vía rápida a literatura pacega, nos deu Cunqueiro unha visión moito máis fonda, orixinal e auténtica do substrato do País (Gonsar 1991).

El propio Cunqueiro en una entrevista concedida a Antón Risco e Ignacio Soldevila subraya el caracter específico de su trilogía de relatos breves al indicar que es su obra más claramente dirigida al lectorado gallego.

Hai algúns libros meus como Escola de menciñeiros, Tesouros novos e vellos e Xente de Aqui e acolá...Pois, ben nestes libros a min o que me preocupaba era o home galego[...] Nestes libros, eu preocupeime un pouco disto, de dar unha influencia de don Vicente Risco en moitas cousas, ata en certo sentido do humor ou de ver un tipo determinado, etcétera. Don Vicente en min influíu moito (nos outros libros non me dirixo xa ó lector especificamente galego) (Risco y Soldevila 1991).

Frente a esta común valoración Xoán González Millán advierte, sin embargo, de que el éxito del Cunqueiro más etnográfico y antropológico revela la sobrecarga ideológica que el canon literario galego padece convirtiendo a la literatura en un espacio privilegiado para la producción de signos étnicos. Así, refiriéndose a Os outros feirantes, el estudioso afirma:

[...] é esta obra menor de Cunqueiro, a pesar do humor e a ironía que el sempre lle impón a toda a súa producción literaria, unha proposta de narrativa esencialista, instrumentalizada para definir en profundidade (dentro da tradición do etnomarabilloso) unha determinada colectividade que nese momento esixía propostas de identidade imaxinaria máis complexas, e polo tanto menos tópicas [...] É, en resumo, o texto dun clásico da narrativa galega que, sen embargo, nada aportaba, a fins dos 70, ao panorama de renovación da narrativa galega posfranquista. Atrás quedaban proxectos novelísticos como El año del Cometa (1974) do mesmo autor, que de ter sido escrito en galego sería considerado un texto fundacional para as novas xeracións de escritores, e tería contribuído de forma decisiva ao anovamento da narrativa galega dos oitenta (González Millán 1996: 151). 


\subsection{Del “¿Quiénes somos?” al "Nosotros somos así”. Reducción pragmática y lectura de grupo}

La propia dimensión etnográfica del texto de partida parece condicionar en la versión castellana un tipo de modalidad enunciativa en la que el autor-traductor se configura como un intermediario o portavoz entre dos universos referenciales diferentes. De hecho, en la maniobra de trasvase tiene lugar un cambio de finalidad de la obra. Así, si en el original Cunqueiro elabora un mundo narrativo destinado a la colectividad gallega con el propósito fundacional de interrogarse acerca de los rasgos identitarios del país (¿Quiénes somos? es la pregunta que anima el planteamiento de la obra), en la versión, por el contrario, se produce un cambio de perspectiva. Ahora primará el objetivo de la divulgación de la realidad gallega en el resto del Estado (Nosotros somos así). La peculiaridad de esta situación, en la que el narrador-traductor declara su pertenencia al universo referencial del texto original, sin dejar por ello de actuar como eficaz intermediario cultural, es posible en la medida en la que, tal y como prueban los siguientes ejemplos, existe una identificación entre las voces de narrador, autor y traductor:

Cuando escribí mi Escuela de curanderos, se me olvidaron Mel de Vincios, Pita de San Cobade, y un discípulo de Mel, un tal Lousas, que yo no sé si vive o murió, que fue quien me contó de su maestro, que yo no lo he conocido. (Gente, p. 35)

Me visitó en mi casa de Vigo un sobrino de Novo de Parmuide, que iba a embarcar en el paquebote portugués Santa María. (Gente p. 39)

Era el año 32, y yo acababa de publicar mi primer libro de poemas [...] Yo en la fatuidad adolescente, me enorgullecía suponiendo que había llegado hasta Parmuide la fama de mi primer libro de poemas (Gente, p. 40)

A Louredo lo he conocido, como a tanta otra gente, en la barbería de mi amigo Pallarego (Gente, p. 91)

Hay muchas historias con paraguas en mi provincia gallega (Gente, p. 107)

De hecho, esta triple dimensión del locutor del texto de llegada es consecuencia directa de la configuración de la voz narrativa del texto de partida. En Xente de Aquí e acolá, así como en los otros volúmenes integrantes de lo que se ha dado en denominar la "trilogía de relatos gallegos": Escola de Menciñeiros y Os Outros Feirantes, se observa cómo el propio Cunqueiro, ficcionalizado como narrador, aprovecha la fuerza realista que se deriva de la apariencia biográfica para crear un mundo fabulado. Por lo tanto, a la hora de abordar la versión al castellano es lógico o hasta cierto punto esperable que el narrador, identificado con el autor, introduzca comentarios del tipo: "los gallegos les llamamos", "lo que los gallegos llamamos", "como le decimos los gallegos"..., que revelan la consciencia del cambio de destinatario. La voz del narrador de la traducción se hace pues audible, al tiempo que traza una imagen clara del lector castellano de acuerdo con el modelo de ethos de mediación explícita sugerido por Suchet.

A continuación nos detendremos en dos de los aspectos que consideramos más relevantes en cuanto a la visibilización del enunciador como locutor segundo del 
texto autotraducido: el tratamiento de los referentes culturales y el reflejo de la alteridad lingüística.

\subsection{El tratamiento de los referentes culturales}

Tanto los nombres propios como aquellos términos que designan la especificidad de una cultura en relación con su medio físico contribuyen poderosamente al anclaje referencial de un texto. La traducción debe elegir entonces entre conservar, trasvasar o naturalizar los referentes, una operación en la que se vuelve especialmente visible la tensión entre dos matrices culturales.

En general, las modificaciones causadas por el cambio de destinatario en La otra gente pueden localizarse en relación con términos pertenecientes a las referencias geográficas, los antropónimos, las fiestas y romerías populares y las costumbres y actividades tradicionales.

\subsubsection{Referencias geográficas}

Pese a la clara ubicación geográfica del mundo descrito en Xente de Aquí e Acolá, las tierras de la montaña luguesa próximas al Mondoñedo natal, Cunqueiro muestra en su traducción un cierto cuidado en evitar aquellas referencias excesivamente locales. Así, dentro de su labor de simplificación y adaptación del texto, el escritor puede optar por alterar el topónimo original para substituirlo por otro que, probablemente, suponga más conocido:

[...] e entón camiñaba ate Foz (Xente, p.152)

[...] y entonces paseaba hasta Ribadeo (Gente, p. 172)

Sin embargo, lo más habitual es que las alteraciones que presenta la traducción manifiesten la tendencia a suprimir las referencias concretas para optar por una descripción genérica:

[...] sabíase as serras, a Corda e máis o Cadramón. (Xente, p. 108)

[...] sabía los caminos todos de las sierras vecinas (Gente, p. 121)

[...] cando ía de Lurres a Lugo, polo camiño de Pacios (Xente, 127)

[...] Cuando iba de viaje (Gente, 142)

Entre los modos de presentación de los protagonistas de Xente de aquí e acolá es frecuente encontrar su designación por medio del nombre propio y el topónimo (Penedo de Rúa, Mel de Vincios, Louzao de Mouride...) Este tipo de designación, propio de las zonas rurales, da pie en ocasiones a unha breve descripción del medio físico en el que se desarrolla la vida del personaje. La información que se proporciona indica la familiaridad con la que el narrador se dirige al lector implícito, que presupone perteneciente al mismo ámbito geográfico. El cambio de destinatario altera lógicamente los presupuestos que rigen la situación enunciativa. Al desaparecer la relación de familiaridad con el narratario, Cunqueiro opta por suprimir pasajes como los siguientes: 
O camposanto de Seixo está por detrás da eirexa, no mediodía daquel outeiro, e medra nel un grande e vello teixo, con raíces e sombra pro indiviso entre todos os fideles difuntos que alí xacen (Xente, p. 51)

unha lama verde que cando enche tras as chuvias do inverno chega ao van das abidueiras, cobre o camiño de Noste, e anega as terras que noutrora foron liñaregas e agora son prados e maizais (Xente, p. 154)

E ao chegar ao chan atravesa unha chousa, as máis das veces feita unha lama, na que hai unha ducia de vellos castiñeiros e tamén uns amieiros. (Xente, p. 56)

El caríz minucioso y detallista de las descripciones obedece al recurso, tantas veces utilizado por el autor, a un estilo trufado de datos anecdóticos que contribuyen a propiciar la evocación del mundo narrado. La decisión de eliminar estos pasajes en la traducción al castellano puede venir motivada por la suposición de la falta de efectividad de esta estrategia en lectores ajenos al mundo referencial descrito.

En la decisión de la supresión de estas referencias influye también el deseo de una mayor depuración en el proceso de reescritura. El modelo de la narración oral en el que se inspira el autor lo lleva a organizar sus relatos mediante pequeños detalles o anécdotas que parecen ir enhebrándose de acuerdo con el flujo asociativo del pensamiento. Las digresiones pormenorizadoras, al tiempo que confieren verosimilitud a lo narrado, producen una cierta descompensación formal. Enfrentado por segunda vez a su texto, el autor tiende a perfeccionar la simetría estructural del relato eliminando los pasajes más accesorios.

A menudo esta depuración comporta la desaparición no solo de la descripción geográfica sino también de la anécdota que suscita:

Da parte de arriba está a carballeira de Rodil. Polido espricóume que a mandara plantar Carlos III, pra coa madeira dos seus carballos facer barcos no ferrol. Carlos II, que según Polido era un rei moi puntual, mandou pedir un informe sober dos ventos domiñantes, a humidade ambente e a cras de terreo (Xente, p. 64)

As casas de Rubias están nun alto, onde foi un castro que catalogou don Federico Menciñeira e os Andrade tiveron por acolá unha torre (Xente, p.112)

Existen también ocasiones en las que la supresión de la descripción parece deberse a la propia natureza del comentario:

As casas están no fondal do val, onda o río, no que chaman o Chao. A primeira casa, sempre mui encaleada, é o muiño de Porteiro. O río é un pequeno afluente do Sor, un ledo brincador, e máis abaixo do muíño remansa pra servir de espello ás abidueiras e máis aos salgueiros. A aldea de Mouros é probe, e a repoboación forestal deixóu aos mouregos sin o gado do monte. A xente nova foise toda, pra Suiza e Alemaña, e drento de pouco non haberá Mouros, e non se verá dende a Portela, acolá embaixo, o fume azul das chimeneas.(Xente, p. 129)

Como vemos, este pasaje muestra una visión crítica de la realidad gallega. El comentario del narrador subraya las consecuencias negativas que el fenómeno de la emi- 
gración tiene para el país. Probablemente esta vertiente de denuncia, excepcional en la escritura cunqueiriana, no se adecue a la imagen que el escritor pretende difundir en el ámbito estatal. Así, eliminará las alusiones a los conflictos sociales y económicos para proporcionar una representación idealizada de la Galicia rural, propia de determinada proyección que, como bien analiza Manuel Forcadela en su ensaio Diálogos na néboa: Álvaro Cunqueiro e Ramón Piñeiro na xénese da literatura galega de posguerra (2005) está en sintonía con la causa del galleguismo que representa el ámbito de la Generación Galaxia y el modelo ideológico encarnado en la figura de Ramón Piñeiro.

\subsubsection{Antropónimos}

La propia configuración de la voz narrativa de Xente de aquí e acolá como la de un narrador testigo perteneciente al mundo diegético implica un alto grado de familiaridad con los personajes descritos, que, a menudo, tienen una existencia real. La apariencia biográfica de los relatos y el modo de transmisión que, imitando el modelo de la tradición oral, perfila como narratario del discurso a un lector-oyente pertenciente al mismo ámbito referencial, el de las comarcas del norte lugués, marca al texto con una fuerte carga de implícitos. La importancia de las presuposiciones, es decir, de aquella información no verbalizada porque el locutor la da ya por conocida por el receptor, se hace especialmente patente en el caso de los nombres propios. Sin embargo, los cambios enunciativos entre el original y la traducción modifican esta perspectiva. Así, Cunqueiro optará por clarificar las referencias nominales:

[...] a muller levóuno a Primo de Baltar (Xente, p. 42)

[...] la mujer lo llevó a que lo viese un curandero llamado Primo de Baltar (Gente, p. 44)

[...] a que o mirase o Dr. Somoza (Xente, p. 77)

[...] a que lo viese un psiquiatra, el doctor Somoza, que era de familia conocida de Lugo (Gente, p. 84)

o bien decidirá suprimirlas:

[...] na barbería do Pallarego (Xente, p. 90)

[...] en la barbería (Gente, p. 103)

[...] con receta de médico, é dicir, do curador Pita de Sancobade, que aínda vive, e é mui hixiénico e dado a lacticinios (Xente, p. 113)

[...] por medicina (Gente, p. 125)

[...] e que pra un abogado de Lugo como Pepe Benito ou de Madrid como Soto Reguera non tiña precio (Xente, p. 14)

[...] y que para un abogado famoso no tendría precio (Gente, p. 14) 
Mención aparte merecen aquellas referencias en las que el protagonista es el propio Cunqueiro ficcionalizado como personaje. Aprovechando el efecto de realidad que se deriva de la apariencia biográfica, el autor acostumbra a proporcionar datos sobre su propia vida. Estas alusiones se incrementan en la versión castellana. La sospecha del desconocimiento de su itinerario creativo en la cultura española probablemente sea el motivo que justifica la aparición de referencias como la que sigue:

Era el año 32, y yo acababa de publicar mi primer libro de poemas [...] Yo en la fatuidad adolescente, me enorgullecía suponiendo que había llegado hasta Parmuide la fama de mi primer libro de poemas (Gente, p. 40)

\subsubsection{Fiestas y romerías populares}

Las fiestas y romerías tienen una importante presencia en el mundo rural retratado por Xente de aqui e acolá, un mundo donde estos acontecimientos acostumbran a vertebrar la vida social de la comunidad. En la traducción estas referencias tienden a adecuarse a las coordenadas de un receptor ajeno al mundo descrito. Así, podemos encontrar una paráfrasis explicativa que substituye a la referencia concreta:

[...] que lle apetecía algo de biscoito, si non lle quedara do San Martiño (Xente, p. 27)

[...] que le apetecia algo de bizcocho, si le quedaba del almuerzo del patrón (Gente, p. 28)

o bien una amplificación que explicita aquello que se daba por sobreentendido en el original:

Unha vez, polo San Pedro de Riotorto (Xente p. 38)

Una vez, en la fiesta de San Pedro, en Riotorto (Gente, p. 38)

[...] á feira de Villalba (Xente, p. 78)

[...] a la feria de diecinueve de diciembre a Villalba (Gente, p. 174)

\subsubsection{Costumbres o tradiciones gallegas}

Entre las adiciones que presenta la versión castellana de Xente de aqui e acolá sobresalen aquellas que ofrecen información suplementaria sobre tradiciones o costumbres del país. Es en estos añadidos donde se observa con mayor claridad la función de intermediación cultural con la que el autor aborda la reescritura de su texto. Esto es detectable en pasajes como el siguiente:

Hay muchas historias con paraguas en mi provincia gallega. Como historias de cuervos, y como dije de éstas, que quizás también debiera reunir las del paraguas. Todas las historias de paraguas que conozco suponen que los paraguas vuelan. Quizás debió haberle volado el paraguas al primero que lo usó en el país, y de ahí 
vendrá la imaginación, o la memoria. En fin, como a mí me gusta contar variado, van sueltas las historias de cuervos y las historias de paraguas (Gente, p. 107)

El comentario que sirve de introducción al relato "Seixo de Parderrubias" incide en la dimensión etnográfica que presenta el libro. El narrador parece subrayar con su intervención una determinada imagen del país gallego que responde al horizonte de expectativas del nuevo lector.

La función documental se percibe también en el añadido de informaciones que sorprenden por su especificidad:

$\mathrm{O}$ anano rañábao a dúas mans, cos dous pulgares, que parece que sexa ésta a cortesía do rañar, e non á mangarra (Xente, p. 20)

El enano lo rascaba a dos manos, con los dos pulgares, que ésta parece, a juzgar por las manos de rascar, de madera de boj o de abedul, corrientes en Galicia, que sea la cortesía del buen rascar, y no a la mangarra, como se rascan entre sí los maragatos (Gente, p.19)

Este mismo carácter divulgativo se encuentra en aclaraciones que resultan redundantes en el contexto en el que se insertan:

[...] de paso os húngaros lle ensinaran a guisar os coscos. A primeira vez que eu escoitéi que se comían os coscos foi ao señor cura de Oubelle. Decíalle a un tío meu: -Ese amigo teu, o Ruzos, come os coscos. Esas cousas deberían confesarse, coño, o mesmo que o sesto! (Xente, p. 155)

[...] y de paso los húngaros le enseñaron a comer los caracoles. En Galicia comer caracoles sorprende. La primera vez que yo supe que se comían los caracoles, fue escuchándole al señor cura de Oubelle decirle a un tío mío:

-Ese amigo tuyo, Ruzos, come los caracoles. ¡Esas cosas, coño, debían confesarse como el sexto! (Gente, p. 174)

A veces, las informaciones culturales se ofrecen mediante el añadido de nuevas anécdotas, lo que contribuye a enriquecer la ficción:

El gallego que más capones cobró de renta fue un obispo de Orense en el siglo XII, don Lourenzo, que no arrendaba ni la menor parcela de tierra episcopal sin poner de renta un capón (Gente, p. 87)

Teodoro Carlos o que quería saber era, verbigracia, como se mandaban partes escritos os galegos antergos (Xente, p.168)

Teodoro Carlos lo que quería saber era, por ejemplo, cómo se mandaban partes escritos los gallegos antiguos de los castros. Le pedí que me llevase con él al monte, que yo copiaría los signos, los compararíamos con los que vienen en el Corpus Petrogliphorum de Galicia (Gente, p. 188) 


\subsection{El reflejo de alteridad lingüística}

A pesar de que el procedimiento más habitual sea el de la supresión, adaptación o aclaración de los términos o conceptos que pudiesen resultar extraños al lector castellano, en ocasiones Cunqueiro opta por ofrecer un equivalente funcional para después añadir un comentario en el que se da noticia de la voz gallega. Este procedimiento, únicamente posible en la medida en la que existe una identificación entre las voces del narrador, el autor y el traductor, indica un deseo de mantener la alteridad lingüística insertándola en el cuerpo del texto.

Tal y como apunta Vázquez Ayora:

Hay así mismo, en toda clase de textos, casos en que es necesario conservar valores, percepciones y prácticas de la otra cultura por su importancia simbólica, porque son valores que enriquecen a la lengua receptora, y porque si se los altera, el mensaje pierde su carácter. En esos casos se efectúa la transición por varios medios, entre ellos, la "modificación externa" o la "aposición especificativa". Esto puede ocurrir cuando no se encuentra una forma apropiada de equivalencia o de adaptación, o cuando conviene conservar a la vez el "color local", para de esta manera no incurrir en el "calco cultural”. (Vázquez Ayora 1977: 328)

Este procedimiento de glosa o de traducción revela, sin duda, la actuación del modelo "dar a conocer" apuntado por la tipología propuesta por Lagarde (2001: 53-55) para la mediación en la escritura bilingüe. El poder de significancia que el autor percibe en su lengua vernácula, vivida como una parte esencial de su identidad, le lleva a rechazar la posibilidad de equivalencia plena en la otra lengua, al tiempo que se convierte en una oportunidad de dar visibilidad a la cultura dominada. A caballo entre la iniciación lingüística y la explicación etnológica o antropológica, la solución de hacer convivir el término y su traducción o glosa da como resultado una cierta redundancia semántica entre dos códigos que se complementan y que, como indica Grutman se dirigen, implícitamente, a un lector no bilingüe, sino diglósico:

Le texte diglossique aussi se distingue du texte bilingue. Dans ce dernier, strictement parlant, l'irruption de la langue étrangère n'est pas encadrée, amortie, neutralisée par une batterie de traductions ou de paraphrases. Il n'y a pas de redondance sémantique entre des codes linguistiques qui se complètent et font donc implicitement appel à un lecteur bilingue5. Dans les textes diglossiques, par contre, la coprésence des langues fonctionne différemment parce qu'elle repose sur une certaine redondance (Grutman 2003: 8)

La presencia de glosas que convocan el término gallego en La Otra Gente puede obedecer a motivos variados. En ocasiones es la propia especificidad cultural de la palabra la que parece difícil de trasvasar al otro idioma. Este sería, por ejemplo, el caso de pelotas de amoado:

[...] os bos criadores danlle de propina [ós capós], unha ou dúas veces ó día, tras as pelotas de amoado, media copiña de viño doce (Xente, p. 78) 
[...] los buenos criadores, después de las pelotas que les meten en el gaznate -pelotas de harina, de leche, que llamamos amoado-, los regalan con media copita de vino dulce (Gente, p. 87)

A veces es el propio relieve simbólico del término, que designa una realidad emblemática del país, como el instrumento de la gaita o la celebración ligada a las castañas otoñales, lo que parece animar a Cunqueiro a reproducir la voz gallega:

E as palletas da gaita súa eran italianas (Xente, p. 134)

Las lengüetas de su gaita -los gallegos les llamamos "palletas"- eran italianas (Gente, p. 150)

Axudaba a varear nas castañas e sempre aos rapaces lles facía un magosto (Xente, p. 142)

[...] y era muy hábil en hacer braseros para asar las dulces castañas de allí, en pleno. Lo que los gallegos llamamos "magostar" (Gente, p. 159)

En otros casos, sin embargo, el préstamo obedece a un comentario de índole metalingüística en el que se subraya la expresividad o eufonía del término vernáculo, al tiempo que se llama la atención sobre el valor de una realidad idiomática frecuentemente ignorada o menospreciada.

O golpe falaba mui ben o galego, e co acento de alí mesmo, onde dicen autro por outro e aira por eira (Xente, p. 46)

El zorro, raposo o golpe, como le decimos los gallegos, hablaba muy bien nuestra lengua, y con el acento de aquella misma comarca, donde dicen autro por outro, otro, y aira por eira, era (Gente, p. 163)

[...] pasando polos tesouros escusados nas lamas (Xente, p.19)

[...] pasando por los tesoros escondidos en las lagunas que allí llaman lamas (Gente, p. 19)

[...] e o merlo mesmo do seu mote (Xente, p. 74)

[...] y el mirlo mismo de su apodo, merlo en nuestro romance gallego (Gente, p. 81)

Como se puede comprobar, el comentario epilingüístico, si bien prescinde de la adjetivación, muy habitual, según Lagarde, en este tipo de escritura bilingüe (2001: 54), no deja de enfatizar el valor. La propia mención a la lengua adquiere una importancia cardinal. La denominación lingüística vehicula por sí misma el carácter extranjero de la lengua convocada. Y es que, como subraya Patrick Sériot:

A partir du moment où une langue a un nom, elle devient un objet homogène, non plus un ensemble dans un diasystème, mais objet de politique linguistique, d'édu- 
cation, enjeu de la constitution d'un État-Nation. Elle devient aussi, et surtout, objet de discours, qu'il est si facile de confondre avec un objet du monde (Sériot 1997: 167).

\section{Conclusión}

Ante la encrucijada entre adaptación o retención de elementos foráneos, Cunqueiro escogerá una vía intermedia. El propio carácter de autotraducción facilita la visibilización de un mediador, el propio autor convertido en personaje, que, erigiéndose en representante de una comunidad, "da a conocer" su realidad lingüística y cultural. Sin embargo, y pese al uso del plural inclusivo "nosotros los gallegos" dirigido al público endógeno, el punto de vista dominante en el texto parece plegarse en ocasiones a la visión estereotipada que de Galicia se tiene en el imaginario estatal. La supresión de toda referencia conflictiva (pensemos, por ejemplo, en el pasaje suprimido en el que se describen las huellas de la emigración), o el claro incremento de la informacion de tipo etnográfico y antropológico, que modela el mundo referencial de acuerdo con un arcádico (y arcaico) ruralismo hacen que el nuevo texto manifieste una escritura que oscila entre el exotismo condescendiente del tipo "color local" y la voluntad de "dar a conocer" del primero y segundo de los modos de escritura bilingüe apuntados por Lagarde (2001).

La reescritura del autor, transmutado en traductor, aplica así una lectura reduccionista que tiende a resaltar el nivel pragmático convirtiendo en un programa de conocimiento lo que en el original era, sobre todo, una recreación ficcional marcada por el recurso a lo fantástico. Esta operación, que se ve facilitada, sin duda, por el propio género de "semblanzas" en el que la obra se inscribe, informa también acerca de los mecanismos que rigen en la construcción del discurso sobre el otro en un estado pluricultural como es el español. Así, la presencia del heterolingüismo, que hace audible la mediación, puede considerarse una característica habitual en muchas autotraducciones peninsulares en las que la que la nota o la glosa aparecen incorporadas en el cuerpo mismo del texto alterando el estatus de la ficción. En la base de este fenómeno se halla, a mi juicio, la particular concepción de "extranjería" de las lenguas peninsulares cooficiales, un grado de distancia "menor" que supone, de hecho, una aceptación tácita de su pertenencia a un espacio cultural común.

Esta tolerancia hacia la alteridad lingüística acostumbra a presentar también fuertes límites. Como apunta Grutman:

[...] la tolérance ou l'intolerance à l'égard de l'interference linguistique signalent une ouverture ou au contraire une fermeture qui a tout à voir avec les relations de pouvoir asymétriques entre les langues et les pays qui les parlent. (2003: 63)

Dentro de un marco de relaciones de poder como lo son las relaciones entre las literaturas gallega, catalana y vasca con la de expresión castellana, tienden a asumirse como tolerables solo aquellos textos que ocultan el conflicto sociolingüístico propio de las situaciones de contacto. Formas como el hibridismo o la interlengua con ethos de mediación rechazada, por emplear la terminología de Suchet (2010: 11-12) no tienen, pues, el mismo grado de aceptación por el común del lectorado de la lengua dominante. 
Otra de las conclusiones a las que lleva este acercamiento a la versión castellana La otra gente tiene que ver con las tendencias que actúan con fuerza específica en las autotraducciones intraestatales ${ }^{7}$. La propia ambigüedad del tipo de extranjería en la que se inscriben lleva a que dos de las fuerzas básicas que operan en toda autotraducción: la naturalización y el descentramiento (Oustinoff: 2001) vean acentuados sus perfiles conviviendo a menudo en el seno del mismo texto. En el caso de Cunqueiro podemos observar claramente cómo, juntamente con el afán por reproducir la alteridad lingüística y cultural, este tiende a allanar las dificultades de recepción, previendo, en muchas ocasiones con un celo excesivo, las reacciones del lector monolingüe en español.

El autotraductor, configurado como mediador explícito que cumple el papel de representante global de una colectividad, se muestra, pues, muy permeable a aceptar los axiomas que fundamentan la mirada del dominante sobre el dominado y a acentuar, por lo tanto, el tipismo en una lectura simplificadora. Al mismo tiempo, la textualización de la situación diglósica lo lleva a desarrollar una enunciación bífida que busca la complicidad con el lector endógeno dibujando una cartografía que, a menudo, devuelve la imagen de una especificidad cultural subalterna.

\section{Referencias bibliográficas}

Casanova, Pascale (2002): “Consécration et accumulation de capital littéraire. La traduction comme échange inégal". Actes de la recherche en sciences sociales, 144-2: 7-20.

Cunqueiro, Álvaro (1990): Xente de aquí e de acolá. Vigo: Galaxia (1ª edición 1971).

Cunqueiro, Álvaro (1991): La otra gente. Barcelona: Destino ( $1^{a}$ edición 1975).

Gonsar, Camilo (1991): "Cunqueiro e a Joie de Vivre”, Diario 16 de Galicia, 30/11.

González Millán, Xoán (1996): A narrativa galega actual (1975-1984). Unha historia social. Vigo: Xerais.

Grutman, Rainier (1997): Des Langues Qui Résonnent: L’hétérolinguisme Au XXème Siècle Québécois. Québec: Fides.

Grutman, Rainier (2003): "Bilinguisme et diglossie: comment penser la différence linguistique dans les littératures francophones?", en Les études littéraires francophones: état des lieux, L. D’hulst y J.M. Moura (dir.), pp. 113-126. Lille: Presses Universitaires de Lille.

Grutman, Rainier (2005): "La textualisation de la diglossie dans les littératures francophones", en Des cultures en contact. Visions de l'Amérique du Nord francophone, Jean Morency, Hélène Destrempes, Denise Merkle y Martin Pâquet (eds.). Québec: Éditions Nota bene.

Grutman, Rainier (2011): "Diglosia y autotraducción vertical (en y fuera de España)", en Aproximaciones a la traducción, Xosé Manuel Dasilva y Helena Tanqueiro (eds.), pp. 69-91. Vigo: Editorial Academia del Hispanismo,

Grutman, Rainier (2012): “Traduire 1'hétérolinguisme: questions conceptuelles et con)textuelles", in Hétérolinguisme et traduction. Autour d'Olive Senior, Marie-Annick Montout (dir.), p. 49-81. Angers: Presses de 1'Université d'Angers.

Forcadela, Manuel (2005): Diálogos na néboa: Álvaro Cunqueiro e Ramón Piñeiro na xénese da literatura galega de posguerra. Santiago de Compostela: Centro Ramón Piñeiro para a investigación en humanidades.

A este respecto resulta muy útil consultar la monografía de Josep Miquel Ramis dedicada a la autotraducción y, en especial el capítulo titulado "Factors i motivacions de la autotraducció" (Ramis 2014: 32-70). 
Kerbrat-Orecchioni, Catherine (2002): "Rhétorique et interaction", en Après Perelman: quelles nouvelles politiques pour les nouvelles rhétoriques?, Koren et Amossy (eds.), pp. 173-196. Paris: L'Harmattan.

Lagarde, Christian (2001): Des écritures “bilingües”. Sociolinguistique et littérature. Paris: L'Harmattan.

Lane-Mercier, Gillian (1989): La Parole romanesque. Paris: Klincksieck.

Losada, Basilio (1980): "Narrativa gallega de posguerra", Camp de l'arpa, 75: 46.

Mackey, William (1976): "Langue, dialecte et diglossie littéraire”, en Diglossie et littérature, Henri Giordan y Alain Ricard (dir.), pp. 19-50. Bordeaux: Maison des Sciences de l'homme d'Aquitaine.

Maingueneau, Dominique (1999). "Ethos, scénographie, incorporation”, en Images de soi dans le discours. La construction de l'ethos, Amossy, Ruth (dir.), pp. 75-101. Lausann : Delachaux et Niestlé.

Oustinoff, Michael (2001): Bilinguisme d'écriture et auto-traduction. Julien Green, Samuel Beckett, Vladimir Nabokov. París: L'Harmattan.

Ramis, Josep Miquel (2013): "La autotraducción y el difícil encaje de sistemas literarios en contacto". Eu-topías: revista de interculturalidad, comunicación y estudios europeos, 5 : 99-111.

Ramis, Josep Miquel (2014): Autotraducció. De la teoria a la pràctica. Vic: Eumo Editorial. Risco, Antón y Soldevila, Ignacio (1991): “Álvaro Cunqueiro: «A imaxinación é santidade”. La Voz de Galicia, 29/12.

Santoyo, Julio César (2012): “Autotraducciones: ensayo de tipología”, en Al humanista, traductor y maestro Miguel Ángel Vega Cernuda, Pilar Martino Alba, Juan A. Albadalejo, Martha Pulido (eds.), pp. 205-222. Madrid: Editorial Dykinson.

Seriot, Patrick (1997): "Faut-il que les langues aient un nom?", en Le nom des langues I, Les enjeux de la nomination des langues, Andrée Tabouret-Keller (éd.), p.167. Louvain-La-Neuve: Peeters.

Suchet, Myriam (2009): “Traduire Juan sin Tierra: une histoire d'ethos" www.uottawa.ca/associations/act.../Suchet_Traduire_Juan_sin_Tierra.pdf $>$ (Consulta 3 de marzo de 2016).

Suchet, Myriam (2010): Textes hétérolingues et textes traduits : de "la langue aux figures de l'énonciation. Pour une littérature comparée différentielle, Tesis de doctorado. https:// www.theses.fr/139711732 (Consulta el 8 de septiembre de 2017).

Suchet, Myriam (2014) : L'Imaginaire hétérolingue. Ce que nous apprennent les textes à la croisée des langues. Paris: Classiques Garnier.

Vázquez-Ayora, Gerardo (1977): Introducción a la traductologia. Washington: Georgetown University Press.

Villanueva, Darío (1993) "A intencionalidade do realismo en Cunqueiro", en Actas do Congreso Álvaro Cunqueiro, pp. 349-360. Santiago de Compostela: Xunta de Galicia. 